Economic estimation of construction of snow-removing ditches using the amount of snow damage has been made in an urban area of $20.45 \mathrm{~km}^{2}$. Construction is economical in the commercial district and neighborhood in a year of snow scarcity, and also in years of snow abundance in residential districts.

\section{ACKNOWLEDGEMENTS}

We thank Nagaoka City Office which supplied much of the data used. This study was supported in part by members of the Conference of Development and Research for an Integrated System of Removal, Storage and Airconditioning Use of Snow.

\section{REFERENCE}

Umemura, T., S. Kamimura and H. Otaki. 1992. Snow damage on an urban area with heavy snow fall: definition of the amount of snow damage and appraisal. Journal of Natural Disaster Science, 13(1), 111.

The accuracy of references in the text and in this list is the responsibility of the authors, to whom queries should be addressed.

\title{
Utilization of snow with a snow compactor
}

\author{
NOBUO MIYAZAKI, \\ Climate Engineering Inc., 541-4, Saiho, Nakasato-Ville., Naka-Uonuma, Niigata 949-84, Japan \\ TOSIYUki Harada, Sigeru Kondou, \\ Kannsai Electric Power Co. Inc., 3-22, 3-Chome, Nakanosima, Kita-ku, Osaka 530, Japan \\ TATUO HASEMI \\ Science of Snow and Ice Co. Ltd., 1-9, 3-Chome, Azabudai, Minato-ku, Tokyo 106, Japan
}

\section{SUMMARY}

In recent years many attempts have been made to utilize snow in the snowy areas of Japan. Among basic technologies for snow utilization, compaction and shaping of snow are important in order to use storage space effectively and to delay snow melt.

A snow compactor with a "screw-feed" system was developed: collected natural snow is compressed by a screw into a solid cylindrical snow column. Extrusion speed of the compressed column is about $60 \mathrm{~cm} \mathrm{~min}^{-1}$ and the productivity of this snow compressor is over $0.5 \mathrm{th}^{-1}$.

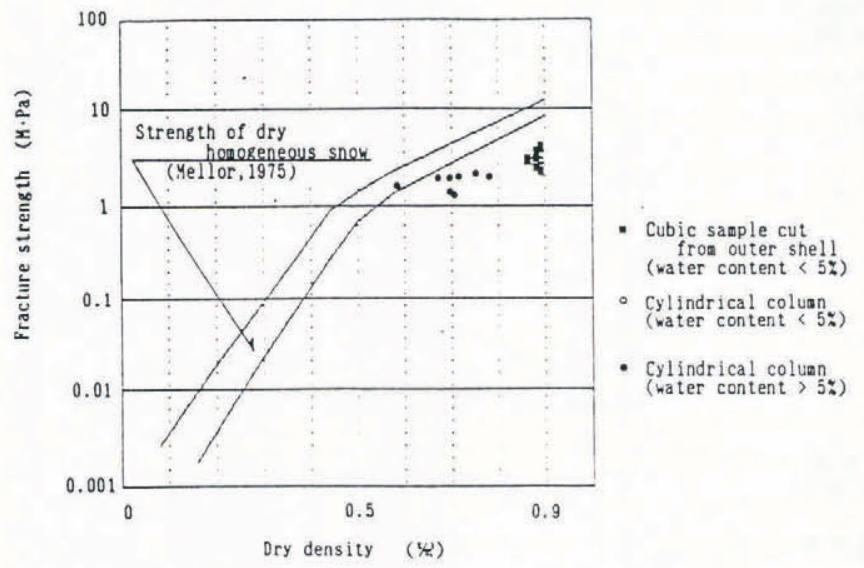

Fig. 1. Compressive fracture strength (samples tested immediately after extrusion).

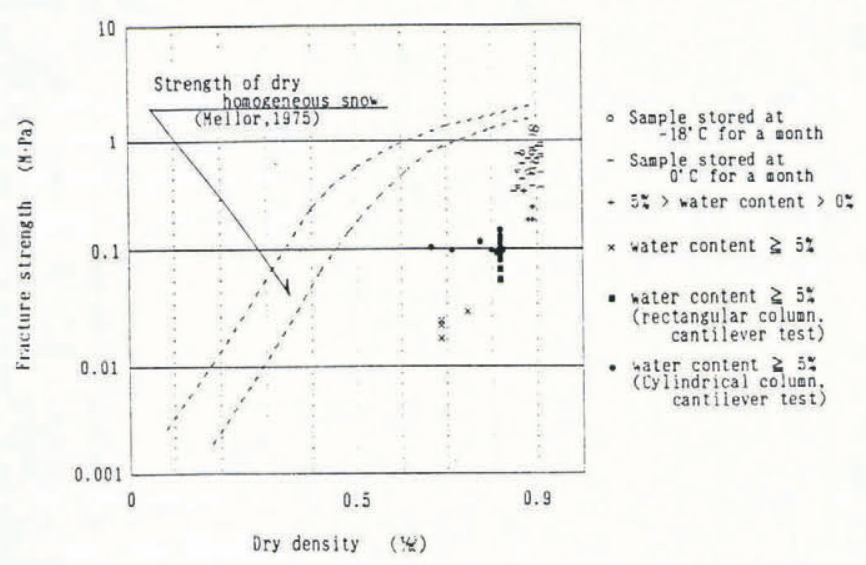

Fig. 2. Tensile fracture strength.

The wet density of the compacted columns is over $790 \mathrm{~kg} \mathrm{~m}^{-3}$. Pressure at the screw blades is 15$30 \mathrm{kgf} \mathrm{cm}^{-2}$ during continuous production of snow columns.

The cross-section of a compacted-snow column is circular or rectangular. The center part of the column, where coarse ice grains are observed, is mechanically weak and thought to be less compacted. The outer shell of the column is more transparent with many small air bubbles.

Wet density of the resultant snow column was measured as $790-940 \mathrm{~kg} \mathrm{~m}^{-3}$, which is two to four times greater than the original snow density. Water content was 
about $8 \%$ for the natural snow and around $10 \%$ for the resultant compacted column.

Results of mechanical test are shown in Figure 1 with dry snow as a reference (Mellor, 1975). Fracture strength increases with decreasing water content. Observed strength of all is less than one half of the dry snow strength. Measured tensile strength is shown in Figure 2. For the snow columns immediately after extrusion, tensile strength decreases with increasing water content. For the stored samples, frozen snow columns show similar strength to the homogeneous dry specimens, and columns stored at $0^{\circ} \mathrm{C}$ show rather smaller values than frozen ones.

Compacted-snow columns are weak immediately after compression before snow grains have time to bond. Storing the snow columns at $0^{\circ} \mathrm{C}$ may increase their strength. Mechanical tests indicate that stored columns can be used as building materials (e.g. in snow festivals) or for storage of snow.

\section{ACKNOWLEDGEMENTS}

We are grateful to Dr Tadayuki Ohnuma and Professor Katutoshi Tushima, Dr Tsutomu Nakamura and Dr Toshiich Kobayashi for much advice during the test. Thanks are also due to Professor Shunichi Kobayashi and Dr Kaoru Izumi for the use of their cold room and compressive-test machine.

\section{REFERENCE}

Mellor, M. 1975. A review of basic snow mechanics. International Association of Hydrological Sciences Publication 114 (Symposium at Grindelwald 1974 - Snow Mechanics), 251-291.

The accuracy of references in this list and in the text are the responsibility of the authors, to whom queries should be addressed.

\title{
Geomorphological features and distribution of avalanche furrows in heavy snow regions in Japan
}

\author{
Tatsuo Sekiguchi, Masanori Sugiyama and Tadao Hoya \\ Geographical Survey Institute, Ministry of Construction, Kitasato-1, Tsukuba, Ibaraki, 305 Japan
}

\section{SUMMARY}

Slopes where full-depth avalanches often occur have characteristic features which have not been described in detail. We define an "avalanche furrow" as a steep convergent furrow which on aerial photographs looks like a pattern scratched by a needle. We have researched morphological features of avalanche furrows and relationships between avalanches and avalanche furrows using photo interpretation and field survey of study areas in Hokuriku district, central Japan, and the distribution of avalanche furrows based on interpretation of $1: 15000$ scale photos in the whole of Japan.

Avalanche furrows usually appear in groups of two to four. Each is composed of smoothly dissected rock.

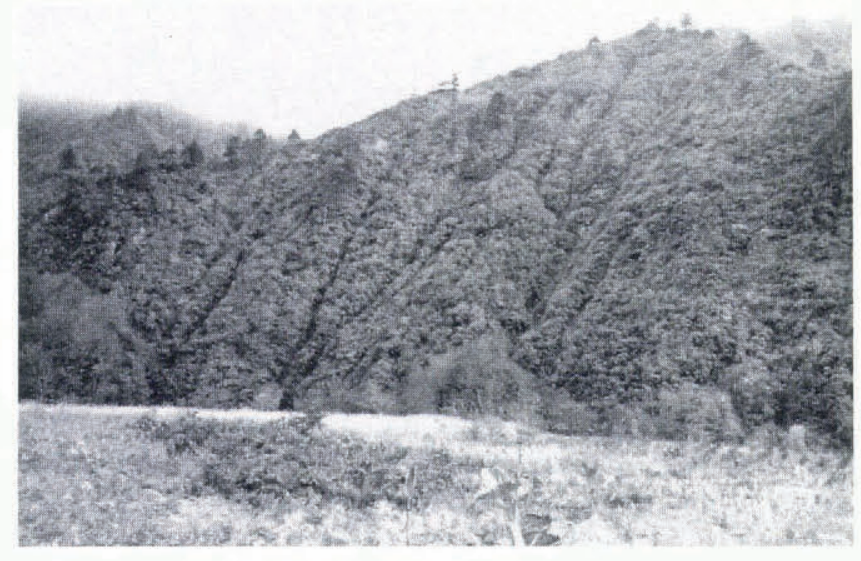

Fig. 1. Terrestrial photograph of "avalanche furrow".
Usually semicircular or U-shaped in section, they are 3$6 \mathrm{~m}$ wide and $2-3 \mathrm{~m}$ deep, and slightly concave in longitudinal section. Lengths range from several tens to several $100 \mathrm{~m}$, and continue from near the ridge line to valley floor (Fig. 1).

Avalanche furrows appear on $76.8 \%$ of slopes where avalanches have occurred. Inversely, traces of avalanches appear in $90.2 \%$ of avalanche furrows. Distribution of inclination of avalanche furrows is centered at $35^{\circ}-50^{\circ}$, while that of non-avalanche furrows where avalanches occurred is concentrated from $30^{\circ}$ to $45^{\circ}$. Avalanche furrows are distributed in heavy snow regions of Japan, especially densely in Hokuriku district and the southern part of Tohoku district. They are good indicators of slopes where avalanches will easily occur.

"Avalanche chutes" (Shimokawa, 1980) appear in slopes where avalanches occur, formed by avalanches and distributed centrally in areas where avalanche furrows appear. We have not investigated their genesis, but we concluded from their distribution that they too are formed by avalanching snow.

\section{REFERENCE}

Shimokawa, K. 1980. Geomorphic study of avalanche chute in the upper drainage basin of the Tadami River. Geographical Review of Japan, 53(3), 171-188.

The accuracy of references in the text and in this list is the responsibility of the authors, to whom queries should be addressed. 